\title{
Epigallocatechin-3-Gallate Attenuates the Effects of TNF- $\alpha$ in Vascular Endothelial Cells by Causing Ectodomain Shedding of TNF Receptor 1
}

\author{
Won Seok Yang ${ }^{\mathrm{a}}$ Soo Young Moon ${ }^{\mathrm{b}}$ Mee Jeong Lee ${ }^{\mathrm{c}}$ Su-Kil Park \\ aDivision of Nephrology, Department of Internal Medicine, Asan Medical Center, College of Medicine, \\ University of Ulsan, Seoul, bAsan Institute for Life Sciences, Seoul, 'Department of Pediatrics, College of \\ Medicine, Dankook University, Cheonan, Korea
}

\section{Key Words}

A disintegrin and metalloprotease $10 \cdot$ Calcium influx $•$ Cyclopiazonic acid $\bullet$ Epigallocatechin3-gallate $\cdot$ Thapsigargin $•$ Tumor necrosis factor receptor 1

\begin{abstract}
Background/Aims: We investigated the mechanism underlying anti-tumor necrosis factor- $\alpha$ (TNF- $\alpha$ ) effects of epigallocatechin-3-gallate (EGCG) in human aortic endothelial cells. Methods: Tumor necrosis factor receptor 1 (TNFR1) was assessed by Western blot analysis. Cytosolic $\mathrm{Ca}^{2+}$ was measured using Fluo-4 AM. A disintegrin and metalloprotease 10 (ADAM10) was localized by immunofluorescence staining. Results: EGCG caused ectodomain shedding of TNFR1 within 30 min and attenuated TNF- $\alpha$-induced endothelin-1 (ET-1) expression. EGCG-induced TNFR1 ectodomain shedding was prevented by BAPTA-AM (intracellular $\mathrm{Ca}^{2+}$ chelator), but not by the absence of extracellular $\mathrm{Ca}^{2+}$. In physiologic extracellular $\mathrm{Ca}^{2+}$ concentration, EGCG markedly increased cytosolic $\mathrm{Ca}^{2+}$. Even in the absence of extracellular $\mathrm{Ca}^{2+}, \mathrm{EGCG}$ raised cytosolic $\mathrm{Ca}^{2+}$, though less potently. siRNA depletion of ADAM10 prevented EGCG-induced ectodomain shedding of TNFR1 and also diminished the inhibitory effect of EGCG on TNF- $\alpha$-induced ET-1 expression. EGCG caused translocation of ADAM10 to the plasma membrane, and this effect was prevented by BAPTA-AM. Besides extracellular $\mathrm{Ca}^{2+}$ influx, release of intracellular stored $\mathrm{Ca}^{2+}$ caused ADAM10-dependent ectodomain shedding of TNFR1. Conclusion: EGCG decreases the responsiveness of cells to TNF- $\alpha$ by causing ADAM10-dependent ectodomain shedding of TNFR1. This effect was attributed to its property to increase cytosolic $\mathrm{Ca}^{2+}$ through both extracellular $\mathrm{Ca}^{2+}$ influx and release of stored $\mathrm{Ca}^{2+}$.
\end{abstract}




\section{Introduction}

Epigallocatechin-3-gallate (EGCG) is a catechin that is abundant in green tea [1]. In animal and human studies, it had beneficial effects on autoimmune disease [2], atherosclerosis [3, 4] and cancer [5, 6]. In vitro studies have revealed that EGCG exerts diverse biological effects on the cells through regulation of cellular signaling as well as anti-oxidative action [7].

Tumor necrosis factor- $\alpha$ (TNF- $\alpha$ ) is a pro-inflammatory cytokine that has a pivotal role in the development of atherosclerosis [8] and cancer [9] as well as immune-mediated disease [10]. One of the biologic actions of EGCG is to attenuate the effects of TNF- $\alpha$. EGCG was shown to inhibit TNF- $\alpha$-induced productions of fractalkine, chemokine (C-C motif) ligand 2 and plasminogen activator inhibitor- 1 in human umbilical vein endothelial cells [11-13]. It also inhibited TNF- $\alpha$-induced expression of vascular cell adhesion molecule- 1 in human aortic endothelial cells (HAECs) and thereby prevented TNF- $\alpha$-stimulated monocyte adhesion [14]. Besides, EGCG protected against TNF- $\alpha$-mediated lung inflammation in mice [15]. It is well-known that TNF- $\alpha$ stimulates the generation of reactive oxygen species (ROS) and activates transcriptional factors including nuclear factor $-\kappa B(N F-\kappa B)$ to increase the transcription of target genes [16]. As the mechanisms of the anti-TNF- $\alpha$ effects, EGCG was shown to suppress the generation of ROS or inhibit NF- $\kappa B$ [11-15].

To exert the cellular effects, TNF- $\alpha$ should bind to the receptors on the cell surface. Two different receptors, tumor necrosis factor receptor 1 (TNFR1) and 2, mediate the signaling of TNF- $\alpha$ [17]. Recently, we found that extracellular $\mathrm{Ca}^{2+}$ influx, induced by vitamin $\mathrm{D}_{3}$ or an L-type calcium channel agonist Bay K8644, causes a disintegrin and metalloprotease (ADAM) 10-mediated ectodomain shedding of TNFR1 in human aortic smooth muscle cells $[18,19]$. The shedding of TNFR1 ectodomain results in decreased responsiveness of the cells to TNF- $\alpha$ by reducing the number of receptors on the cell surface. In addition, the released ectodomain portion of TNFR1 may bind to TNF- $\alpha$ in the extracellular space and neutralize its activity [20]. Although the mechanisms are not completely elucidated, EGCG also increases cytosolic $\mathrm{Ca}^{2+}$ in vascular smooth muscle cells and endothelial cells by extracellular $\mathrm{Ca}^{2+}$ influx or release from endoplasmic reticulum (ER) storage $\mathrm{Ca}^{2+}$ [21-23]. Thus, we hypothesized that EGCG may have anti-TNF- $\alpha$ effects by causing ectodomain shedding of TNFR1 through $\mathrm{Ca}^{2+}$-dependent activation of ADAM10.

Endothelin-1 (ET-1) is a potent vasoconstrictive peptide produced by vascular endothelial cells [24]. Its effects on vascular smooth muscle cells are implicated in diverse vascular diseases such as hypertension and atherosclerosis [24]. In our previous study [25], TNF- $\alpha$ was shown to stimulate ET-1 production in HAECs.

In the present study, therefore, we investigated whether EGCG causes ectodomain shedding of TNFR1 in HAECs and thereby attenuates the stimulatory effect of TNF- $\alpha$ on ET-1 expression.

\section{Materials and Methods}

\section{Materials}

EGCG, thapsigargin, cyclopiazonic acid, calcium chloride, 4', 6-diamidino-2-phenylindole dihydrochloride (DAPI) and 1,2-bis(o-aminophenoxy)ethane-N,N,N',N'-tetraacetic acid)-acetoxymethyl ester (BAPTA-AM) were purchased from Sigma-Aldrich (St. Louis, MO, USA). EGCG was dissolved in phosphate buffered saline (PBS). TNF- $\alpha$ was from R\&D Systems (Abingdon, UK). Antibodies to human ADAM10 and actin were from Santa Cruz Biotechnology (Santa Cruz, CA, USA). Antibodies to human TNFR1 (ab19139; raised against synthetic peptides corresponding to amino acids 29-43 of human TNFR1 in the N-terminus) and ET-1 were from Abcam, Inc. (Cambridge, MA, USA). ADAM10-siRNA, control-siRNA (Ambion ${ }^{\circledR}$ ) and Fluo4 AM (Molecular probes ${ }^{\circledR}$ ) were from Life Technologies (Paisley, UK).

Cell culture

HAECs were obtained from Lonza Walkersville, Inc. (Walkersville, MD, USA). The cells were cultured in EBM-2 endothelial growth basal medium (Lonza Walkersville, Inc.). Before each experiment, the cells were 


\section{Cellular Physiology Cell Physiol Biochem 2016;38:1963-1974 \begin{tabular}{l|l} 
DOI: 10.1159/000445557 & $\begin{array}{l}\text { C } 2016 \text { The Author(s). Published by S. Karger AG, Basel } \\
\text { www.karger.com/cpb }\end{array}$ \\
\hline Published online: May 09, 2016 Biochemistry
\end{tabular}}

Yang et al.: EGCG Causes Ectodomain Shedding of TNFR1

rested for $24 \mathrm{~h}$ in RPMI-1640 (Life Technologies) containing $2 \%$ fetal calf serum (Biological Industries Ltd., Cumbernauld, UK) and then the culture medium was replaced with serum-free RPMI-1640 $\left(\mathrm{Ca}^{2+}\right.$ adjusted to $1.2 \mathrm{mM}$ by calcium chloride supplementation) or Dulbecco's modified Eagle's medium (DMEM) $\left(\mathrm{Ca}^{2+} 0\right.$ or $1.2 \mathrm{mM}$ ), as appropriately.

\section{Transfection of siRNA}

siRNA transfection was performed on the cells seeded in a 6-well plate and cultured for $24 \mathrm{~h}$, using Lipofectamine ${ }^{\circledR}$ Reagent (Life Technologies). In brief, 100 pmol siRNAs were incubated with 10 $\mu \mathrm{l}$ of lipofectamine reagent diluted in Opti-MEM ${ }^{\circledR}$ medium (Life Technologies) for 15 minutes at room temperature, by which siRNA-lipofectamine complexes are formed. To perform transfection, siRNAlipofectamine complexes were added to the cells in fresh serum-free culture medium. After $6 \mathrm{~h}$ incubation at $37^{\circ} \mathrm{C}$ in a $\mathrm{CO}_{2}$ incubator, the medium was replaced with complete growth medium containing $10 \%$ fetal calf serum, and the cells were further incubated for $18 \mathrm{~h}$. Thereafter, the cells were subjected to the experiments.

\section{Western blot analysis}

Equal amounts of the cell lysates were separated by sodium dodecyl sulfate-polyacrylamide gel electrophoresis and transferred to an Immobilon-P membrane (EMD Millipore Co., Bedford, MA, USA). The membrane was probed with a primary antibody. Bands were visualized using horseradish peroxidase conjugated secondary antibody and the enhanced chemiluminescence agent (Luminata ${ }^{\mathrm{TM}}$ Forte Western HRP Substrate; EMD Millipore Co.).

To detect TNFR1 in cell culture supernatants, the conditioned media were harvested and concentrated using Amicon ${ }^{\circledR}$ ultra $10 \mathrm{~K}$ centrifugal filter device (EMD Millipore Co.). Thereafter, the samples were subjected to sodium dodecyl sulfate-polyacrylamide gel electrophoresis and immunoblot analysis using an antibody against N-terminus of TNFR1.

\section{Measurement of cytosolic Ca ${ }^{2+}$ by confocal microscopy}

HAECs cultured in a 6-well plate were loaded with Fluo-4 AM $(2 \mu \mathrm{M})$. After gentle washing twice with Hank's balanced salt solution (HBSS), the cells were treated with EGCG, thapsigargin or cyclopiazonic acid in $1.2 \mathrm{mM} \mathrm{Ca}^{2+}$-containing HBSS or $\mathrm{Ca}^{2+}$-free HBSS. The Fluo- 4 in the cells was excited by wavelength at 494 $\mathrm{nm}$ and fluorescence images were captured at $506 \mathrm{~nm}$ in a $20 \mathrm{sec}$ interval for $15 \mathrm{~min}$ using Zeiss LSM710 laser-scanning confocal microscope (Carl Zeiss, Germany). The fluorescence intensities were quantified using ZEN 2011 imaging Software (Carl Zeiss, Germany). The change in intracellular $\mathrm{Ca}^{2+}$ concentration was represented by relative fluorescence intensity compared with the initial value.

\section{Immunofluorescence staining}

To investigate the localization of ADAM10, the cells were washed with PBS, fixed with $4 \%$ paraformaldehyde for $10 \mathrm{~min}$, permeabilized with $0.4 \%$ Triton X-100 in PBS for $5 \mathrm{~min}$, and incubated with 1\% BSA in PBS for 60 min to block nonspecific binding. Thereafter, the cells were incubated with goat antiADAM10 antibody overnight at $4{ }^{\circ} \mathrm{C}$, washed 3 times with PBS and then incubated with FITC-conjugated antigoat IgG secondary antibody. The immunoreactivity for ADAM10 was captured using a confocal microscope.

\section{Statistical analysis}

Data are presented as means \pm SE (standard error), with $n$ representing the number of different experiments. An analysis of variance with Scheffe's multiple-comparison test was used to determine statistically significant differences among the groups. A p value of $<0.05$ was considered statistically significant.

\section{Results}

EGCG attenuates TNF- $\alpha$-induced ET-1 expression

We first examined the effect of EGCG on TNF- $\alpha$-induced ET-1 expression in HAECs. HAECs were pretreated with different concentrations of EGCG for $30 \mathrm{~min}$. Thereafter, the culture media containing EGCG were discarded and replaced with fresh media without EGCG, 


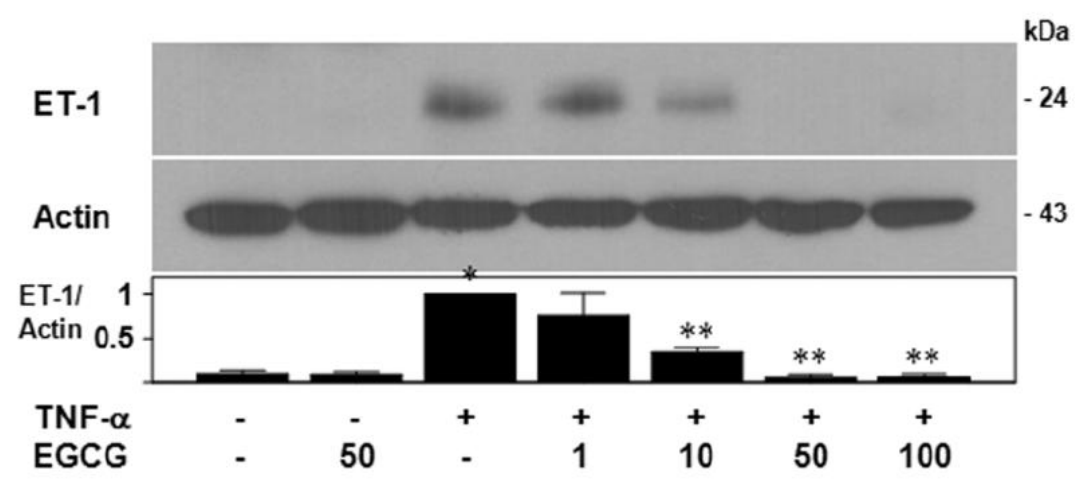

Fig. 1. EGCG attenuates TNF- $\alpha$-induced ET-1 expression. HAECs were incubated with different concentrations of EGCG for $30 \mathrm{~min}$ in RPMI-1640 containing $1.2 \mathrm{mM} \mathrm{Ca}^{2+}$. Thereafter, the media containing EGCG were discarded and replaced with fresh RPMI-1640 without EGCG, and the cells were stimulated with TNF- $\alpha$ (10 $\mathrm{ng} / \mathrm{ml}$ ) for $24 \mathrm{~h}$. Whole cell lysates were analyzed by Western blotting using anti-ET-1 and anti-actin antibodies. ( $\mathrm{n}=3,{ }^{*} \mathrm{p}<0.05$ compared with control; ${ }^{* *} \mathrm{p}<0.05$ as compared with TNF- $\alpha$ ).

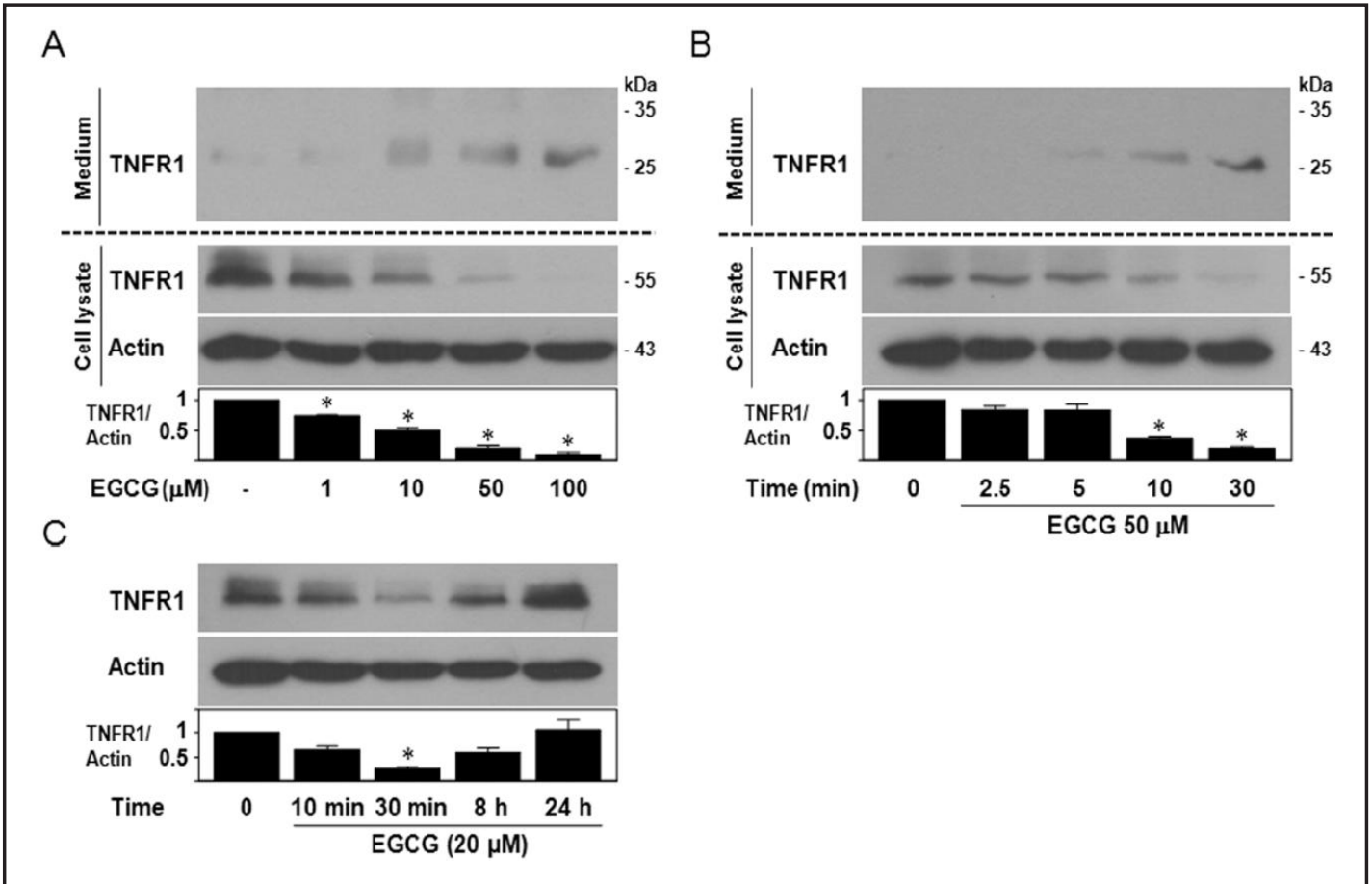

Fig. 2. EGCG causes ectodomain shedding of TNFR1. HAECs in RPMI-1640 containing $1.2 \mathrm{mM} \mathrm{Ca}^{2+}$ were incubated with different concentrations of EGCG for $30 \mathrm{~min}(\mathrm{~A})(\mathrm{n}=4)$, incubated with $50 \mu \mathrm{M}$ of EGCG for 0, $2.5,5,10$ or $30 \mathrm{~min}(\mathrm{~B})(\mathrm{n}=4)$, or incubated with $20 \mu \mathrm{M}$ of EGCG for $0,10 \mathrm{~min}, 30 \mathrm{~min}, 8 \mathrm{~h}$ or $24 \mathrm{~h}(\mathrm{C})(\mathrm{n}=$ $3)$. Whole cell lysates and conditioned media were analyzed by Western blotting using an antibody against the N-terminus of TNFR1. ( $\mathrm{p}<0.05$ compared with control).

and the cells were further incubated with TNF- $\alpha(10 \mathrm{ng} / \mathrm{ml})$ for $24 \mathrm{~h}$. TNF- $\alpha$ increased ET-1 expression, while pretreatment of the cells with EGCG attenuated the stimulatory effect of TNF- $\alpha$ in a dose-dependent manner (Fig. 1).

\section{EGCG causes ectodomain shedding of TNFR1}

To test whether EGCG causes ectodomain shedding of TNFR1, we incubated HAECs with EGCG at the doses of $0,1,10,50$ or $100 \mu \mathrm{M}$ for $30 \mathrm{~min}$ or at the dose of $50 \mu \mathrm{M}$ for 0 , 

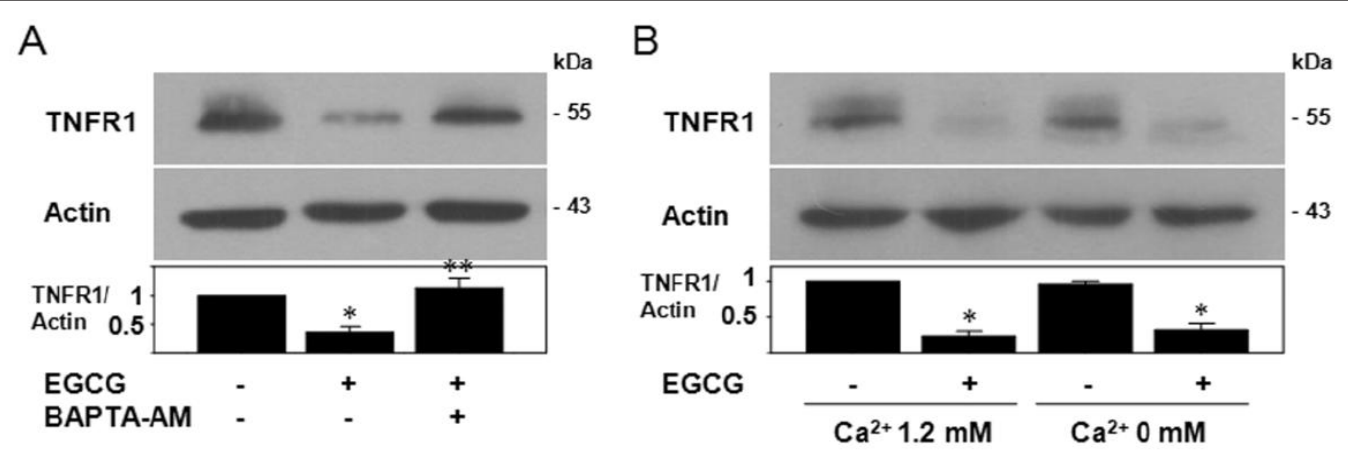

C

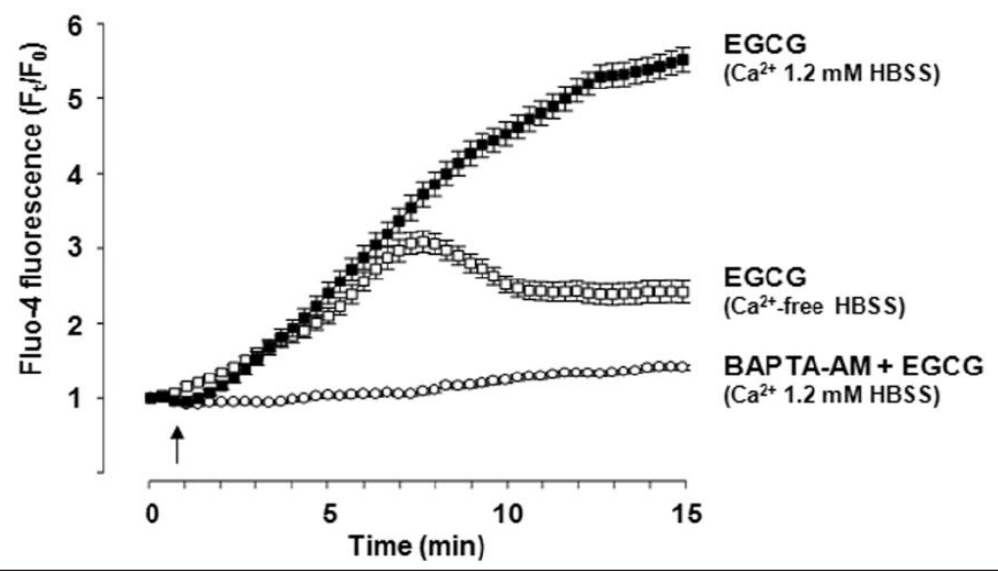

Fig. 3. EGCG-induced TNFR1 ectodomain shedding is dependent on the elevation of cytosolic $\mathrm{Ca}^{2+}$. $(\mathrm{A}, \mathrm{B})$ EGCG-induced TNFR1 ectodomain shedding is prevented by BAPTA-AM, but not by the absence of extracellular $\mathrm{Ca}^{2+}$. (A) HAECs were preincubated with or without BAPTA-AM $(10 \mu \mathrm{M})$ for $30 \mathrm{~min}$, and then further treated with EGCG (50 $\mu \mathrm{M})$ for $30 \mathrm{~min}$ in RPMI-1640 containing $1.2 \mathrm{mM} \mathrm{Ca}^{2+}(\mathrm{n}=3)$. (B) HAECs were incubated with or without EGCG $(50 \mu \mathrm{M})$ for 30 min in DMEM medium containing no $\mathrm{Ca}^{2+}$ or $1.2 \mathrm{mM} \mathrm{Ca}^{2+}(\mathrm{n}=6)$. Whole cell lysates were analyzed by Western blotting using anti-TNFR1 antibody. ( ${ }^{*} \mathrm{p}<0.05$ compared with control; ${ }^{* *}$ p $<0.05$ compared with EGCG). (C) EGCG increases cytosolic $\mathrm{Ca}^{2+}$ by both extracellular $\mathrm{Ca}^{2+}$ influx and release of intracellular storage $\mathrm{Ca}^{2+}$. HAECs were preincubated with or without BAPTA-AM $(10 \mu \mathrm{M})$ for $30 \mathrm{~min}$, and loaded with Fluo-4 AM $(2 \mu \mathrm{M})$, and placed in $1.2 \mathrm{mM} \mathrm{Ca}^{2+}$-containing HBSS or $\mathrm{Ca}^{2+}$-free HBSS. The cells were treated with EGCG $(50 \mu \mathrm{M})$, and intracellular $\mathrm{Ca}^{2+}$ fluorescence intensities were recorded every $20 \mathrm{sec}$ for $15 \mathrm{~min}$. Addition of EGCG is indicated by an arrow. (means \pm SE of $\mathrm{n}=123 \sim 166$ cells in each group from three independent experiments).

$2.5,5,10$ or $30 \mathrm{~min}$, and obtained whole cell lysates and the conditioned media. TNFR1 was measured by Western blot analysis. As shown in Fig. 2A, 2B, EGCG decreased TNFR1 in the cell lysates. TNFR1 released in the culture medium was detected by the antibody recognizing $\mathrm{N}$-terminus of TNFR1, and the band was located at $\sim 25 \mathrm{kDa}$, indicating an N-terminal fragment of TNFR1. In contrast to the cellular TNFR1, TNFR1 in the culture medium was increased by EGCG. These effects of EGCG on TNFR1 were dose-, and time-dependent. Within $30 \mathrm{~min}$, EGCG $(50 \mu \mathrm{M})$ markedly decreased cellular TNFR1.

To assess the prolonged effect of EGCG, we treated the cells with a lower dose of EGCG $(20 \mu \mathrm{M})$ for up to $24 \mathrm{~h}$. Cellular TNFR1 decreased significantly within $30 \mathrm{~min}$ after EGCG treatment, but recovered to the control level at $24 \mathrm{~h}$ (Fig. 2C).

EGCG-induced TNFR1 ectodomain shedding is prevented by BAPTA-AM, but not by the absence of extracellular $\mathrm{Ca}^{2+}$

Next, we explored whether $\mathrm{Ca}^{2+}$ signaling is implicated in the ectodomain shedding of TNFR1 in the cells treated with EGCG. HAECs were preincubated with or without BAPTA- 


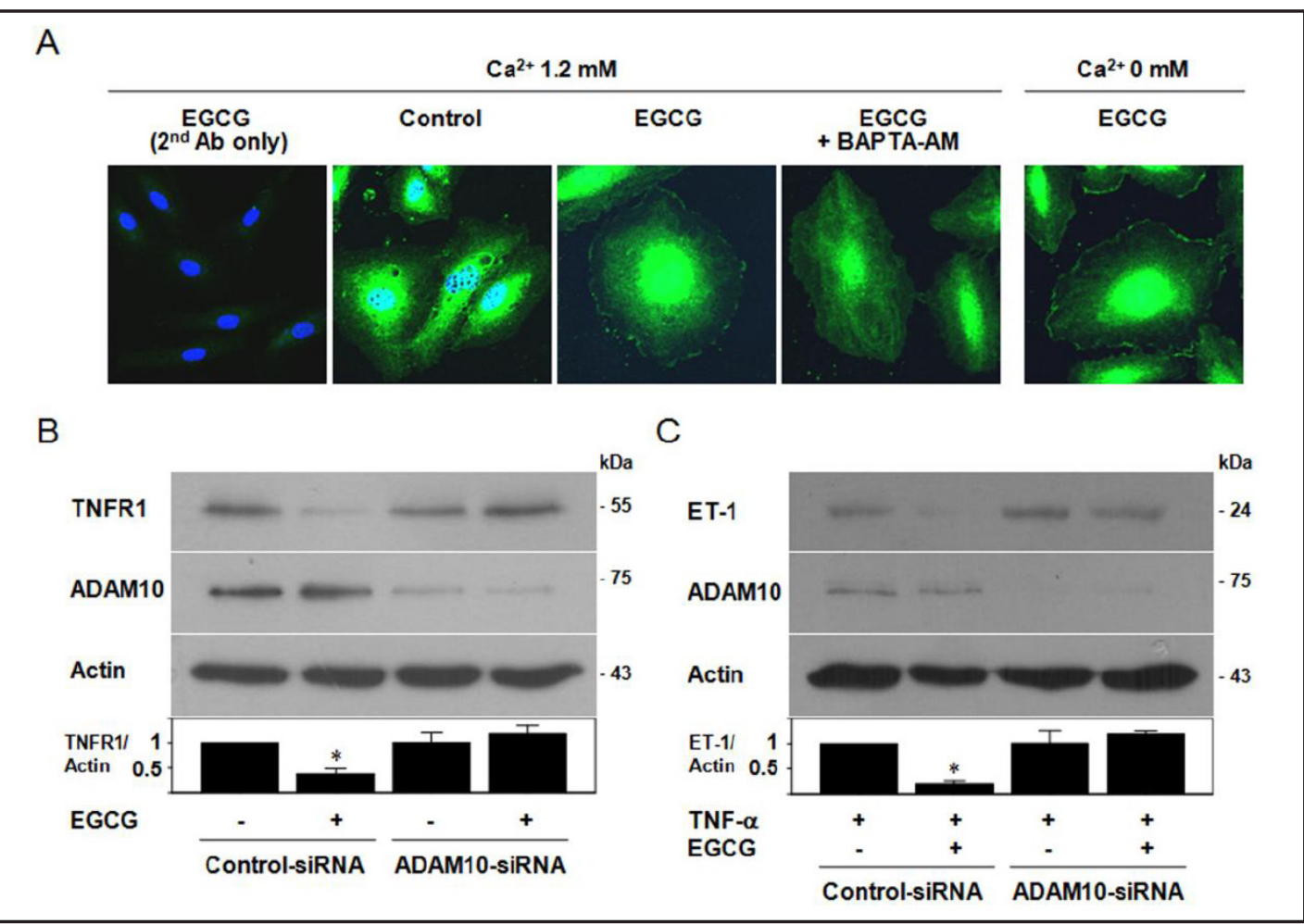

Fig. 4. $\mathrm{Ca}^{2+}$-dependent ADAM10 activation is implicated in the ectodomain shedding of TNFR1. (A) EGCG induces $\mathrm{Ca}^{2+}$-dependent ADAM10 translocation to the plasma membrane. HAECs in DMEM medium containing no $\mathrm{Ca}^{2+}$ or $1.2 \mathrm{mM} \mathrm{Ca}^{2+}$ were preincubated with or without BAPTA-AM $(10 \mu \mathrm{M})$ for $30 \mathrm{~min}$, and then further treated with EGCG $(50 \mu \mathrm{M})$ for $10 \mathrm{~min}$. After then, the cells were fixed with paraformaldehyde, permeabilized with Triton-X, immunostained for ADAM10, and visualized with confocal microscopy. Cell nuclei were stained with DAPI. Representative images from three independent experiments are shown. Notice the ADAM10 immunoreactivity at the surface of the cells treated with EGCG. (B, C) Depletion of ADAM10 abolishes EGCG-induced ectodomain shedding of TNFR1 and the inhibitory effect of EGCG. (B) HAECs were transfected with control-siRNA or ADAM10-siRNA, and then incubated with EGCG (50 $\mu \mathrm{M})$ for 30 min in RPMI-1640 containing $1.2 \mathrm{mM} \mathrm{Ca}^{2+}$. Whole-cell lysates were analyzed by Western blotting using anti-TNFR1, anti-ADAM10 and anti-actin antibodies. ( $n=3,{ }^{*} \mathrm{p}<0.05$ compared with control). (C) HAECs were transfected with control-siRNA or ADAM10-siRNA, and then incubated with or without EGCG $(50 \mu \mathrm{M})$ for 30 min in RPMI-1640 containing $1.2 \mathrm{mM} \mathrm{Ca}^{2+}$. Thereafter the culture media containing EGCG were discarded and replaced with fresh RPMI-1640 without EGCG, and the cells were stimulated with TNF- $\alpha$ (10 ng/ml) for 24 h. Whole cell lysates were analyzed by Western blotting using an anti-ET- 1 antibody. ( $\mathrm{n}=3,{ }^{*} \mathrm{p}<0.05$ compared with control).

$\mathrm{AM}$, an intracellular $\mathrm{Ca}^{2+}$ chelator, for $30 \mathrm{~min}$ and then further treated with EGCG for $30 \mathrm{~min}$. Thereafter, whole cell lysates were analyzed by Western blotting using anti-TNFR1 antibody. As shown in Fig. 3A, the ectodomain shedding of TNFR1 by EGCG was abrogated by BAPTAAM.

To determine whether extracellular $\mathrm{Ca}^{2+}$ influx is essential for EGCG-induced ectodomain shedding of TNFR1, we tested it in $\mathrm{Ca}^{2+}$-free DMEM culture medium. As shown in Fig. 3B, EGCG induced ectodomain shedding of TNFR1 even in the absence of extracellular $\mathrm{Ca}^{2+}$.

EGCG increases cytosolic $\mathrm{Ca}^{2+}$ by both extracellular $\mathrm{Ca}^{2+}$ influx and release of stored $\mathrm{Ca}^{2+}$

Next, we investigated the effect of EGCG on cytosolic $\mathrm{Ca}^{2+}$ level in HAECs, using Fluo-4 $\mathrm{AM}$, a calcium fluorescent indicator (Fig. $3 \mathrm{C})$. In the presence of extracellular $\mathrm{Ca}^{2+}(1.2 \mathrm{mM})$, EGCG greatly increased cytosolic $\mathrm{Ca}^{2+}$ concentration. EGCG-induced elevation of cytosolic $\mathrm{Ca}^{2+}$ was abolished by BAPTA-AM, a cell-permeant chelator for $\mathrm{Ca}^{2+}$. 
Fig. 5. Cytosolic release of stored $\mathrm{Ca}^{2+}$ causes ectodomain shedding of TNFR1. (A) Thapsigargin and cyclopiazonic acid increase cytosolic $\mathrm{Ca}^{2+}$ by release of stored $\mathrm{Ca}^{2+}$. HAECs were loaded with Fluo-4 AM $(2 \mu \mathrm{M})$, and treated with DMSO (vehicle), thapsigargin $(0.2$ $\mu \mathrm{M})$ or cyclopiazonic acid $(2 \mu \mathrm{M})$. The experiments were performed in $\mathrm{Ca}^{2+}$-free HBSS. Time-response traces of intracellular $\mathrm{Ca}^{2+}$ fluorescence intensity are shown. Addition of DMSO, thapsigargin or cyclopiazonic acid is indicated by an arrow. (means $\pm \mathrm{SE}$ of $\mathrm{n}=$ $121 \sim 151$ cells in each group from three independent experiments). (B) Thapsigargin and cyclopiazonic acid cause ectodomain shedding of TNFR1, which is inhibited by intracellular $\mathrm{Ca}^{2+}$ chelator. HAECs were incubated with or without BAPTA-AM $(10 \mu \mathrm{M})$ for $30 \mathrm{~min}$. Thereafter, the culture medium was changed to $\mathrm{Ca}^{2+}$-free DMEM, and the cells were further treated with thapsigargin $(0.2 \mu \mathrm{M})$ or cyclopiazonic acid $(2 \mu \mathrm{M})$ for $30 \mathrm{~min}$. Whole cell lysates and conditioned media were analyzed by Western blotting using anti-TNFR1 antibody. $(\mathrm{n}=3, \mathrm{p}$ p $<0.05$ compared with control; *" $\mathrm{p}<0.05$ compared with thapsigargin; ${ }^{*} \mathrm{p}<0.05$ compared with control; \#\# $<0.05$ compared with cyclopiazonic acid).

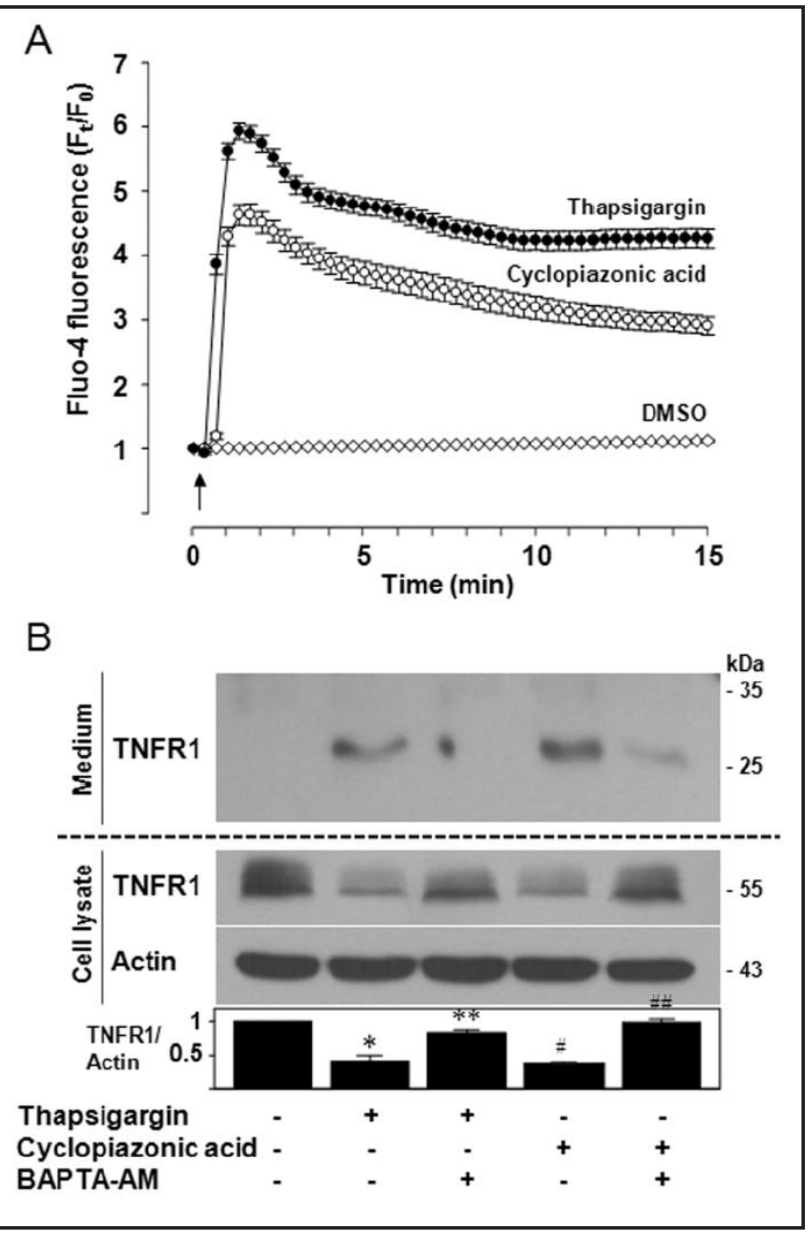

In the absence of extracellular $\mathrm{Ca}^{2+}$, EGCG still increased cytosolic $\mathrm{Ca}^{2+}$, but the potency was lower than that in the presence of extracellular $\mathrm{Ca}^{2+}$.

\section{ADAM10 mediates EGCG-induced ectodomain shedding of TNFR1}

Because calcium influx is known to activate ADAM10 [26], we investigated the role of ADAM10 in EGCG-induced TNFR1 ectodomain cleavage. By immunofluorescent staining and confocal microscopy, the location of ADAM10 was visualized (Fig. 4A). ADAM10 was detected predominantly in the cytoplasm of untreated cells. On treatment with EGCG, ADAM10 immunoreactivity increased at the cell surface. EGCG-induced translocation of ADAM10 to the cell surface was inhibited by BAPTA-AM but not by the absence of extracellular $\mathrm{Ca}^{2+}$.

To determine whether ADAM10 is involved in EGCG-induced ectodomain shedding of TNFR1, we transfected HAECs with control-siRNA or ADAM10-siRNA, and treated them with EGCG. Depletion of ADAM10 prevented the ectodomain cleavage of TNFR1 induced by EGCG (Fig. 4B).

We next investigated whether depletion of ADAM10 reverses the inhibitory effect of EGCG on TNF- $\alpha$-induced ET-1 expression. As shown in Fig. 4C, EGCG could not inhibit TNF$\alpha$-induced ET-1 expression when ADAM10 was depleted by siRNA transfection.

Cytosolic release of stored $\mathrm{Ca}^{2+}$ causes ADAM10-mediated ectodomain shedding of TNFR1

Because EGCG elevated cytosolic $\mathrm{Ca}^{2+}$ even in the absence of extracellular $\mathrm{Ca}^{2+}$ and caused ectodomain shedding of TNFR1, we tested whether cytosolic release of stored $\mathrm{Ca}^{2+}$, using thapsigargin and cyclopiazonic acid, causes ADAM10-mediated ectodomain shedding of TNFR1. Thapsigargin and cyclopiazonic acid elevate cytosolic $\mathrm{Ca}^{2+}$ by inhibiting $\mathrm{Ca}^{2+}$ ATPase that transports cytosolic $\mathrm{Ca}^{2+}$ into ER [27]. 


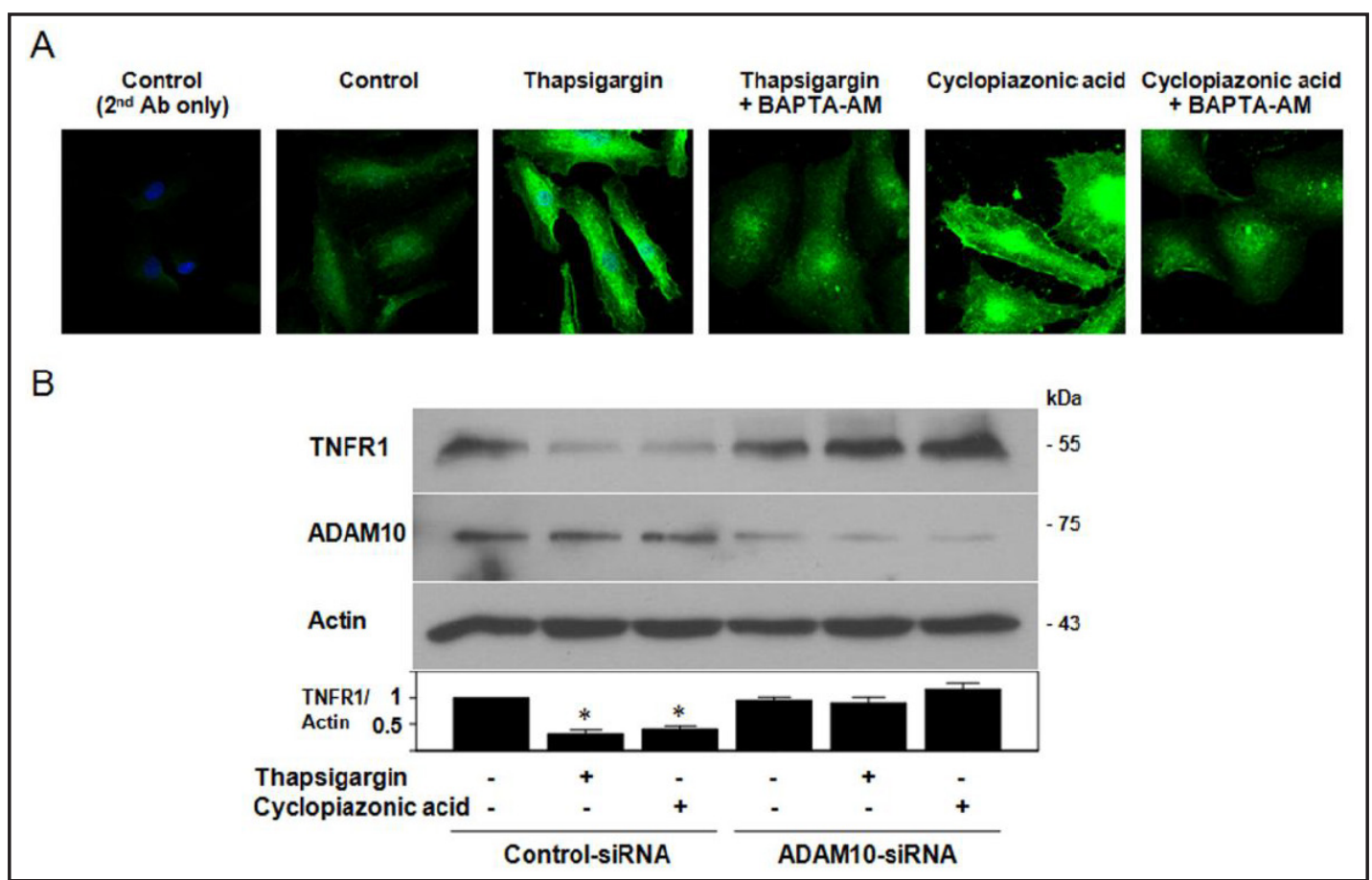

Fig. 6. Cytosolic release of stored $\mathrm{Ca}^{2+}$ activates ADAM10 to cause ectodomain shedding of TNFR1. (A) Thapsigargin and cyclopiazonic acid induce ADAM10 translocation to the plasma membrane. HAECs were incubated with or without BAPTA-AM $(10 \mu \mathrm{M})$ for $30 \mathrm{~min}$. In $\mathrm{Ca}^{2+}$-free DMEM medium, the cells were further treated with thapsigargin $(0.2 \mu \mathrm{M})$ or cyclopiazonic acid $(2 \mu \mathrm{M})$ for $10 \mathrm{~min}$. After then, the cells were fixed with paraformaldehyde, permeabilized with Triton-X, immunostained for ADAM10, and visualized with confocal microscopy. Cell nuclei were stained with DAPI. Representative images from three independent experiments with similar results are shown. Notice the ADAM10 immunoreactivity at the surface of the cells treated with thapsigargin or cyclopiazonic acid. (B) Depletion of ADAM10 abolishes thapsigargin- and cyclopiazonic acid-induced ectodomain shedding of TNFR1. HAECs were transfected with control-siRNA or ADAM10-siRNA. In $\mathrm{Ca}^{2+}$-free DMEM medium, the cells were incubated with thapsigargin $(0.2 \mu \mathrm{M})$ or cyclopiazonic acid $(2 \mu \mathrm{M})$ for $30 \mathrm{~min}$. Whole cell lysates were analyzed by Western blotting using anti-TNFR1, anti-ADAM10 and anti-actin antibodies. ( $\mathrm{n}=4,{ }^{*} \mathrm{p}<0.05$ compared with control).

As shown in Fig. 5A, both thapsigargin and cyclopiazonic acid acutely increased the cytosolic $\mathrm{Ca}^{2+}$ in the absence of extracellular $\mathrm{Ca}^{2+}$. As with EGCG, both thapsigargin and cyclopiazonic acid caused ectodomain shedding of TNFR1, and this effect was inhibited by BAPTA-AM (Fig. 5B).

Next, we examined the involvement of ADAM10 in thapsigargin- and cyclopiazonic acid-induced ectodomain shedding of TNFR1. As shown in Fig. 6A, both thapsigargin and cyclopiazonic acid induced plasma membrane translocation of ADAM10, while BAPTAAM suppressed this effect. On the other hand, depletion of ADAM10 by siRNA transfection prevented thapsigargin- and cyclopiazonic acid-induced ectodomain shedding of TNFR1 (Fig. 6B).

\section{Discussion}

In the present study, we explored the mechanism underlying anti-TNF- $\alpha$ effects of EGCG in HAECs and our data demonstrated that EGCG rapidly causes ectodomain shedding of TNFR1 and thereby attenuates the cellular effect of TNF- $\alpha$. ADAM10 was implicated in the cleavage of TNFR1 ectodomain. This effect of EGCG was attributed to its property to elevate 
cytosolic $\mathrm{Ca}^{2+}$ through both extracellular $\mathrm{Ca}^{2+}$ influx and release of stored $\mathrm{Ca}^{2+}$. The elevated cytosolic $\mathrm{Ca}^{2+}$ triggered the translocation of ADAM10 to the plasma membrane where it may catalyze the cleavage of TNFR1.

TNF- $\alpha$ exerts its biologic effect on the cells through its receptors expressed on the cell surface. EGCG has been shown to suppress the effects of TNF- $\alpha$ in a variety of cell types including vascular endothelial cells [11-15], but it has not been properly investigated whether EGCG has a regulatory effect on TNF receptors. So far, there were two studies that measured the effect of EGCG on the expression of TNFR1 $[13,28]$, in which bovine coronary artery and human umbilical vein endothelial cells were treated with or without EGCG (40 $\mu \mathrm{M}$ ) for $15 \mathrm{~h}$ or $27 \mathrm{~h}$, and TNFR1 in the cells treated with EGCG was not different from that of control cells. In contrast, our data showed that EGCG markedly reduces cellular TNFR1 within $30 \mathrm{~min}$ in a dose-dependent manner at the concentrations between $1 \sim 100 \mu \mathrm{M}$. The reduction of cellular TNFR1 was accompanied by an increase of $\mathrm{N}$-terminal fragment of TNFR1 in cell culture supernatant, indicating that the extracellular domain of TNFR1 is cleaved and shedded into extracellular space. The different findings observed in these studies can be explained by the temporal changes in the cellular level of TNFR1 after EGCG treatment. EGCG rapidly caused ectodomain shedding of TNFR1, but the decreased cellular TNFR1 was recovered to the control level at $24 \mathrm{~h}$, and it may be because the cleaved TNFR1 was replaced later by newly synthesized TNFR1.

BAPTA-AM is permeable to the plasma membrane due to the AM group. Once it is within the cells, the AM group is removed by esterase in the cytoplasm, and then BAPTA is able to chelate $\mathrm{Ca}^{2+}$. In the present study, EGCG increased cytosolic $\mathrm{Ca}^{2+}$, and EGCG-induced TNFR1 ectodomain shedding was dependent on its ability to increase cytosolic $\mathrm{Ca}^{2+}$ because this effect was abolished by BAPTA-AM. Normally, there is a large concentration gradient of $\mathrm{Ca}^{2+}$ across the cell membrane. In extracellular fluid, $\mathrm{Ca}^{2+}$ exists in the range of $1.10-1.35 \mathrm{mM}$ [29], while cytosolic $\mathrm{Ca}^{2+}$ is maintained at much lower concentration (about $100 \mathrm{nM}$ ) in the resting state [30]. This concentration gradient is formed by various calcium pumps. In contrast to low $\mathrm{Ca}^{2+}$ in the cytoplasm, ER contains high concentration of $\mathrm{Ca}^{2+}$ by the action of the sarco- and endoplasmic reticulum $\mathrm{Ca}^{2+}$-ATPase (SERCA) that transports $\mathrm{Ca}^{2+}$ against a concentration gradient, and serves as a storage site of calcium [27]. In response to various stimuli, cytosolic $\mathrm{Ca}^{2+}$ may increase by $\mathrm{Ca}^{2+}$ influx from extracellular fluid or by $\mathrm{Ca}^{2+}$ release from intracellular storage, and acts as a signaling molecule [31]. EGCG has been shown to increase cytosolic $\mathrm{Ca}^{2+}$ in the previous studies. In rat aortic smooth muscle cells [21], EGCG caused extracellular $\mathrm{Ca}^{2+}$ influx via voltage-operated $\mathrm{Ca}^{2+}$ channels and $\mathrm{Ca}^{2+}$-permeable nonselective cation channels. In bovine aortic endothelial cells, EGCG was shown to increase cytosolic $\mathrm{Ca}^{2+}$ by release of ER storage $\mathrm{Ca}^{2+}\left[22\right.$ ] or extracellular $\mathrm{Ca}^{2+}$ influx [23]. Thus, EGCG seems to regulate cytosolic $\mathrm{Ca}^{2+}$ by several different mechanisms. Our data in HAECs were consistent with the previous studies. In the presence of extracellular $\mathrm{Ca}^{2+}$, EGCG markedly increased cytosolic $\mathrm{Ca}^{2+}$. In the absence of extracellular $\mathrm{Ca}^{2+}$, EGCG still raised cytosolic $\mathrm{Ca}^{2+}$. However, the magnitude of increase was less than that in the presence of extracellular $\mathrm{Ca}^{2+}$. Therefore, both extracellular $\mathrm{Ca}^{2+}$ influx and release of storage $\mathrm{Ca}^{2+}$ were considered to contribute to EGCG-induced elevation of cytosolic $\mathrm{Ca}^{2+}$.

The expressions of cell surface receptors and signaling molecules are regulated by ADAMs that cleave the extracellular portion of the transmembrane proteins. So far, 12 proteolytically active ADAMs have been identified [32]. In the present study, EGCG caused translocation of ADAM10 from the cytoplasm to the plasma membrane where TNFR1 is expressed. On the other hand, depletion of ADAM10 by siRNA transfection abolished EGCG-induced TNFR1 ectodomain shedding and also diminished the inhibitory effect of EGCG on TNF- $\alpha$-induced ET-1 production. Thus, ADAM10 was implicated in EGCG-induced ectodomain cleavage of TNFR1.

Extracellular $\mathrm{Ca}^{2+}$ influx, induced by vitamin $\mathrm{D}_{3}$, Bay K8644 or ionomycin, has been shown to activate ADAM10 in our own and other previous studies [18, 19, 33], but it has not yet been verified whether release of intracellular stored $\mathrm{Ca}^{2+}$ also activates ADAM10. In the present study, even in the absence of extracellular $\mathrm{Ca}^{2+}$, EGCG increased cytosolic $\mathrm{Ca}^{2+}$

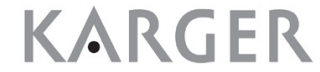


and caused plasma membrane translocation of ADAM10 and induced ectodomain shedding of TNFR1, suggesting that release of storage $\mathrm{Ca}^{2+}$ also activates ADAM10. ER is the major $\mathrm{Ca}^{2+}$ store in the cells [34]. The SERCA inhibitors, thapsigargin and cyclopiazonic acid, are known to block the ability of the cell to pump $\mathrm{Ca}^{2+}$ into ER and acutely raise cytosolic $\mathrm{Ca}^{2+}$ by releasing ER stored $\mathrm{Ca}^{2+}[35,36]$. In the present study, both thapsigargin and cyclopiazonic acid raised cytosolic $\mathrm{Ca}^{2+}$ in the absence of extracellular $\mathrm{Ca}^{2+}$ and caused plasma membrane translocation of ADAM10 and ectodomain shedding of TNFR1, while these effects on ADAM10 and TNFR1 were abolished by BAPTA-AM. On the other hand, depletion of ADAM10 prevented SERCA inhibitor-induced ectodomain shedding of TNFR1. Taken together with our previous studies $[18,19]$, these findings demonstrate that elevation of cytosolic $\mathrm{Ca}^{2+}$ is the trigger factor for ADAM10 activation whether it is caused by influx of extracellular $\mathrm{Ca}^{2+}$ or release of intracellular stored $\mathrm{Ca}^{2+}$.

Vascular inflammation is implicated in the pathogenesis of hypertension [37]. Proinflammatory cytokines, including TNF- $\alpha$, cause endothelial dysfunction leading to reduced vasodilatory responses [38]. In addition, TNF- $\alpha$ stimulates endothelial cells to produce ET-1, a potent vasoconstrictor [25]. Chronic inflammation is also a cardinal feature of atherosclerotic vascular disease $[39,40]$, in which TNF- $\alpha$ plays a critical role in the development of the early lesions of atherosclerosis [8]. In animal studies, EGCG was shown to be effective in preventing endothelial dysfunction, hypertension and atherosclerosis $[3,41]$. In this regard, our data suggest that EGCG may have the beneficial effects on cardiovascular diseases in part by reducing the responsiveness of endothelial cells to TNF- $\alpha$ through ectodomain shedding of TNFR1.

In summary, EGCG elevates cytosolic $\mathrm{Ca}^{2+}$ in HAECs by both extracellular $\mathrm{Ca}^{2+}$ influx and release of stored $\mathrm{Ca}^{2+}$. Elevated cytosolic $\mathrm{Ca}^{2+}$ triggers ADAM10-mediated ectodomain shedding of TNFR1 and thereby reduces the response of the cells to TNF- $\alpha$. By inducing ectodomain shedding of TNFR1, EGCG may downregulate the inflammatory response of vascular endothelial cells.

\section{Acknowledgements}

This study was supported by a grant (02-200) from the Asan Institute for Life Sciences (Seoul, Korea). We thank Han Nam Jeong and Kim Jin Ju for excellent technical assistance.

\section{Disclosure Statement}

The authors declare no potential conflict of interest.

\section{References}

1 Graham HN: Green tea composition, consumption, and polyphenol chemistry. Prev Med 1992;21:334-350.

2 Wu D, Wang J, Pae M, Meydani SN: Green tea EGCG, T cells, and T cell-mediated autoimmune diseases. Mol Aspects Med 2012;33:107-118.

3 Xu X, Pan J, Zhou X: Amelioration of lipid profile and level of antioxidant activities by epigallocatechingallate in a rat model of atherogenesis. Heart Lung Circ 2014;23:1194-1201.

4 Kishimoto Y, Tani M, Kondo K: Pleiotropic preventive effects of dietary polyphenols in cardiovascular diseases. Eur J Clin Nutr 2013;67:532-535.

5 Butt MS, Sultan MT: Green tea: nature's defense against malignancies. Crit Rev Food Sci Nutr 2009;49:463473.

6 Yun M, Lee D, Park MN, Kim EO, Sohn EJ, Kwon BM, Kim SH: Cinnamaldehyde derivative (CB-PIC) sensitizes chemo-resistant cancer cells to drug-induced apoptosis via suppression of MDR1 and its upstream STAT3 and AKT signalling. Cell Physiol Biochem 2015;35:1821-1830. 


\section{Cellular Physiology Cell Physiol Biochem 2016;38:1963-1974 and Biochemistry Published online: May 09, $2016 \quad \begin{aligned} & \text { DOI: 10.1159/000445557 } 2016 \text { The Author(s). Published by S. Karger AG, Basel } \\ & \text { www.karger.com/cpb }\end{aligned}$}

Yang et al.: EGCG Causes Ectodomain Shedding of TNFR1

7 Kim HS, Quon MJ, Kim JA: New insights into the mechanisms of polyphenols beyond antioxidant properties; lessons from the green tea polyphenol, epigallocatechin 3-gallate. Redox Biol 2014;2:187-195.

8 Kleinbongard P, Heusch G, Schulz R: TNF $\alpha$ in atherosclerosis, myocardial ischemia/reperfusion and heart failure. Pharmacol Ther 2010;127:295-314.

9 Atsumi T, Singh R, Sabharwal L, Bando H, Meng J, Arima Y, Yamada M, Harada M, Jiang JJ, Kamimura D, Ogura H, Hirano T, Murakami M: Inflammation amplifier, a new paradigm in cancer biology. Cancer Res 2014;74:8-14.

10 Blandizzi C, Gionchetti P, Armuzzi A, Caporali R, Chimenti S, Cimaz R, Cimino L, Lapadula G, Lionetti P, Marchesoni A, Marcellusi A, Mennini FS, Salvarani C, Girolomoni G: The role of tumour necrosis factor in the pathogenesis of immune-mediated diseases. Int J Immunopathol Pharmacol 2014;27:S1-S10.

11 Lee AS, Jung YJ, Kim DH, Lee TH, Kang KP, Lee S, Lee NH, Sung MJ, Kwon DY, Park SK, Kim W: Epigallocatechin-3-0-gallate decreases tumor necrosis factor- $\alpha$-induced fractalkine expression in endothelial cells by suppressing NF- $\kappa$ B. Cell Physiol Biochem 2009;24:503-510.

12 Wang ZM, Gao W, Wang H, Zhao D, Nie ZL, Shi JQ Zhao S, Lu X, Wang LS, Yang ZJ: Green tea polyphenol epigallocatechin-3-gallate inhibits TNF- $\alpha$-induced production of monocyte chemoattractant protein-1 in human umbilical vein endothelial cells. Cell Physiol Biochem 2014;33:1349-1358.

13 Cao Y, Wang D, Wang X, Zhang J, Shan Z, Teng W: (-)-Epigallocatechin gallate inhibits TNF- $\alpha$-induced PAI-1 production in vascular endothelial cells. J Cardiovasc Pharmacol 2013;62:452-456.

14 Pullikotil P, Chen H, Muniyappa R, Greenberg CC, Yang S, Reiter CE, Lee JW, Chung JH, Quon MJ: Epigallocatechin gallate induces expression of heme oxygenase- 1 in endothelial cells via p38 MAPK and Nrf-2 that suppresses proinflammatory actions of TNF- $\alpha$. J Nutr Biochem 2012;23:1134-1145.

15 Lee IT, Lin CC, Lee CY, Hsieh PW, Yang CM: Protective effects of (-)-epigallocatechin-3-gallate against TNF- $\alpha$ induced lung inflammation via ROS-dependent ICAM-1 inhibition. J Nutr Biochem 2013;24:124-136.

16 Han D, Ybanez MD, Ahmadi S, Yeh K, Kaplowitz N: Redox regulation of tumor necrosis factor signaling. Antioxid Redox Signal 2009;11:2245-2263.

17 Cabal-Hierro L, Lazo PS: Signal transduction by tumor necrosis factor receptors. Cell Signal 2012;24:12971305.

18 Yang WS, Kim HW, Lee JM, Han NJ, Lee MJ, Park SK: 1,25-dihydroxyvitamin D $_{3}$ causes ADAM10-dependent ectodomain shedding of tumor necrosis factor receptor 1 in vascular smooth muscle cells. Mol Pharmacol 2015;87:533-542.

19 Yang WS, Yu H, Kim JJ, Lee MJ, Park SK: Vitamin D-induced ectodomain shedding of TNF receptor 1 as a nongenomic action: $\mathrm{D}_{3}$ vs $\mathrm{D}_{2}$ derivatives. J Steroid Biochem Mol Biol 2016;155:18-25.

20 Wallach D, Engelmann H, Nophar Y, Aderka D, Kemper O, Hornik V, Holtmann H, Brakebusch C: Soluble and cell surface receptors for tumor necrosis factor. Agents Actions Suppl 1991;35:51-57.

21 Campos-Toimil M, Orallo F: Effects of (-)-epigallocatechin-3-gallate in $\mathrm{Ca}^{2+}$-permeable non-selective cation channels and voltage-operated $\mathrm{Ca}^{2+}$ channels in vascular smooth muscle cells. Life Sci 2007;80:2147-2153.

22 Kim HS, Montana V, Jang HJ, Parpura V, Kim JA: Epigallocatechin gallate (EGCG) stimulates autophagy in vascular endothelial cells: a potential role for reducing lipid accumulation. J Biol Chem 2013;288:2269322705.

23 Guo BC, Wei J, Su KH, Chiang AN, Zhao JF, Chen HY, Shyue SK, Lee TS: Transient receptor potential vanilloid type 1 is vital for (-)-epigallocatechin-3-gallate mediated activation of endothelial nitric oxide synthase. Mol Nutr Food Res 2015;59:646-657.

24 Sandoval YH, Atef ME, Levesque LO, Li Y, Anand-Srivastava MB: Endothelin-1 signaling in vascular physiology and pathophysiology. Curr Vasc Pharmacol 2014;12:202-214.

25 Yang WS, Lee JM, Han NJ, Kim YJ, Chang JW, Park SK: Mycophenolic acid attenuates tumor necrosis factor$\alpha$-induced endothelin-1 production in human aortic endothelial cells. Atherosclerosis 2010;211:48-54.

26 Saftig P, Reiss K: The "A Disintegrin And Metalloproteases" ADAM10 and ADAM17: novel drug targets with therapeutic potential? Eur J Cell Biol 2011;90:527-535.

27 Corbett EF, Michalak M: Calcium, a signaling molecule in the endoplasmic reticulum? Trends Biochem Sci 2000;25:307-311.

28 Ahn HY, Xu Y, Davidge ST: Epigallocatechin-3-0-gallate inhibits TNF $\alpha$-induced monocyte chemotactic protein-1 production from vascular endothelial cells. Life Sci 2008;82:964-968.

29 Peacock M: Calcium metabolism in health and disease. Clin J Am Soc Nephrol 2010;5:S23-S30.

30 Guerini D, Coletto L, Carafoli E: Exporting calcium from cells. Cell Calcium 2005;38:281-289. 


\section{Cellular Physiology Cell Physiol Biochem 2016;38:1963-1974 \begin{tabular}{l|l} 
DOI: 10.1159/000445557 & $\begin{array}{l}\text { O 2016 The Author(s). Published by S. Karger AG, Basel } \\
\text { www.karger.com/cpb }\end{array}$
\end{tabular}}

Yang et al.: EGCG Causes Ectodomain Shedding of TNFR1

31 Clapham DE: Calcium signaling. Cell 2007;131:1047-1058.

32 van der Vorst EP, Keijbeck AA, de Winther MP, Donners MM: A disintegrin and metalloproteases: molecular scissors in angiogenesis, inflammation and atherosclerosis. Atherosclerosis 2012;224:302-308.

33 Nagano O, Murakami D, Hartmann D, De Strooper B, Saftig P, Iwatsubo T, Nakajima M, Shinohara M, Saya H: Cell-matrix interaction via CD44 is independently regulated by different metalloproteinases activated in response to extracellular $\mathrm{Ca}^{2+}$ influx and PKC activation. J Cell Biol 2004;165:893-902.

34 Coe H, Michalak M: Calcium binding chaperones of the endoplasmic reticulum. Gen Physiol Biophys 2009;28:F96-F103.

35 Thastrup 0, Cullen PJ, Drøbak BK, Hanley MR, Dawson AP: Thapsigargin, a tumor promoter, discharges intracellular $\mathrm{Ca}^{2+}$ stores by specific inhibition of the endoplasmic reticulum $\mathrm{Ca}^{2+}$-ATPase. Proc Natl Acad Sci U S A 1990;87:2466-2470.

36 Uyama Y, Imaizumi Y, Watanabe M: Cyclopiazonic acid, an inhibitor of $\mathrm{Ca}^{2+}$-ATPase in sarcoplasmic reticulum, increases excitability in ileal smooth muscle. Br J Pharmacol 1993;110:565-572.

37 De Ciuceis C, Rossini C, La Boria E, Porteri E, Petroboni B, Gavazzi A, Sarkar A, Rosei EA, Rizzoni D: Immune mechanisms in hypertension. High Blood Press Cardiovasc Prev 2014;21:227-234.

38 Bautista LE: Inflammation, endothelial dysfunction, and the risk of high blood pressure: epidemiologic and biological evidence. J Hum Hypertens 2003;17:223-230.

39 Viola J, Soehnlein O: Atherosclerosis - A matter of unresolved inflammation. Semin Immunol 2015;27:184193.

40 Cui Y, Xie X, Jia F, He J, Li Z, Fu M, Hao H, Liu Y, Liu JZ, Cowan PJ, Zhu H, Sun Q, Liu Z: Ambient fine particulate matter induces apoptosis of endothelial progenitor cells through reactive oxygen species formation. Cell Physiol Biochem 2015;35:353-363.

41 Potenza MA, Marasciulo FL, Tarquinio M, Tiravanti E, Colantuono G, Federici A, Kim JA, Quon MJ, Montagnani M: EGCG, a green tea polyphenol, improves endothelial function and insulin sensitivity, reduces blood pressure, and protects against myocardial I/R injury in SHR. Am J Physiol Endocrinol Metab 2007;292:E1378-E1387. 